\title{
- Rupture of the sinus of Valsalva due to severe , rheumatoid heart disease
}

\author{
Anthea Howell, Janet Say, and Robin Hedworth-Whitty \\ - From The Middlesex Hospital, London
}

$x$

$A$ case is described of granulomatous rheumatoid heart disease with aortic regurgitation in which haemorrhage into a rheumatoid nodule caused rupture of the sinus of Valsalva and complete

- heart block.

Rheumatoid arthritis may involve the heart. Cardiac nodules, identical histologically to those found in the subcutaneous tissues, were first described by Bagenstoss and Rosenberg

$\downarrow$ in 194I. Since then, some cases have been reported, including some with valve lesions

4 (Weintraub and Zvaifler, 1963; Lassiter and Tassy, 1965) and others with cardiac arrhythmias (Handforth and Woodbury, 1959; Gowans, 1960). We report a fatal case of rheumatoid heart disease with aortic regurgitation and describe the hitherto unrecorded complication of haemorrhage into a rheumatoid nodule which resulted in perforation

of the sinus of Valsalva and the development of a fistula from the aortic root to the right atrium. This destroyed much of the atrioventricular conducting tissue causing terminal complete heart block.

\section{+ Case report}

The patient was a 49-year-old woman who had † suffered from rheumatoid arthritis for five years. The disease was widespread, erosive, nodular, and seropositive with high sheep cell agglutination titres (up to $\mathrm{I} / \mathbf{1 2 8 0}$ ). She had been treated with steroids for three years before her final hospital admission in April 1970, by which time she had

- become severely disabled. While in Chingford Hospital she developed severe dyspnoea, retro4 sternal discomfort, and a sinus tachycardia. For the first time a cardiac murmur was noted, and

- because she also ran a continuous low-grade fever, subacute bacterial endocarditis was suspected and she was transferred to The Middlesex Hospital.

26 Examination The patient showed typical rheumatoid deformities affecting the joints of the , hands, wrists, and knees. There was episcleritis of the right eye and subcutaneous nodules were present. She was dyspnoeic at rest with signs of congestive cardiac failure. The pulse was regular, roo/minute and collapsing in quality, and the blood pressure $120 / 40 \mathrm{mmHg}$. The apex was left ventricular and palpable in the anterior axillary line. A loud early diastolic murmur was present at the left sternal edge and a soft pleuro-pericardial friction rub was also noted. The spleen was not palpable.

Investigations $\mathrm{Hb} \quad \mathrm{I2} \cdot 4 \quad \mathrm{~g} / \mathrm{IOO} \quad \mathrm{ml}$, WBC $\mathrm{r} 4,000 / \mathrm{mm}^{3}$, with a normal differential count. Blood cultures were repeatedly sterile. The Wassermann reaction and tests for lupus erythematosus cells were negative. The chest $x$-ray showed generalized cardiomegaly with evidence of pulmonary oedema. The electrocardiogram confirmed sinus rhythm, with a normal PR interval and no evidence of left ventricular hypertrophy.

Course and treatment In view of the above investigations a diagnosis of rheumatoid heart disease with aortic regurgitation was made. Accordingly, the patient was treated with a standard antifailure regimen, made good progress, and was gradually mobilized. Three weeks after admission, she developed pleuritic chest pain, suggesting pulmonary embolism. This diagnosis was supported by a technetium lung scan, and she was therefore treated with Warfarin and mobilization was continued. Three weeks after this, cardiac arrest occurred. External cardiac massage was carried out and the rhythm was noted to be complete atrioventricular dissociation with periods of ventricular asystole. Transvenous pacing was instituted successfully, but after six hours an intractable ventricular tachycardia developed, followed by irreversible fibrillation.

Necropsy The body showed rheumatoid deformities of many joints and subcutaneous nodules.

There was widespread pleurisy and pericarditis with adherence of the pericardium over the pos- 
terior surface of the heart. The heart weighed $745 \mathrm{~g}$ and showed left ventricular hypertrophy and dilatation. The endocardium of the left ventricle contained numerous superficial, smooth, pale nodules up to $0.7 \mathrm{~cm}$ in diameter (Fig. I). These extended across the posterior wall and interventricular septum up to the base of the aortic valve, where there was an area of haemorrhage with a small central perforation situated behind the noncoronary cusp. A probe could be passed from behind the noncoronary cusp (Fig. 2) through this haemorrhagic area and into the right atrium above the medial commissure of the tricuspid valve (Fig. 3). There was thickening of all three cusps of the aortic valve particularly the right coronary cusp, which was rigid and distorted resulting in nonalignment and regurgitation. The coronary arteries showed obliterative calcific atheroma in all three main branches. There was no evidence of aortitis.

Histology Sections of the nodular area of endocardium and adjacent myocardium showed numerous granulomata in different stages of development. Some of these showed the features of fully developed rheumatoid nodules, and had round or serpiginous outlines with a central area of eosinophilic necrotic material which was

FIG. I Left ventricular endocardial surface showing rheumatoid nodules.

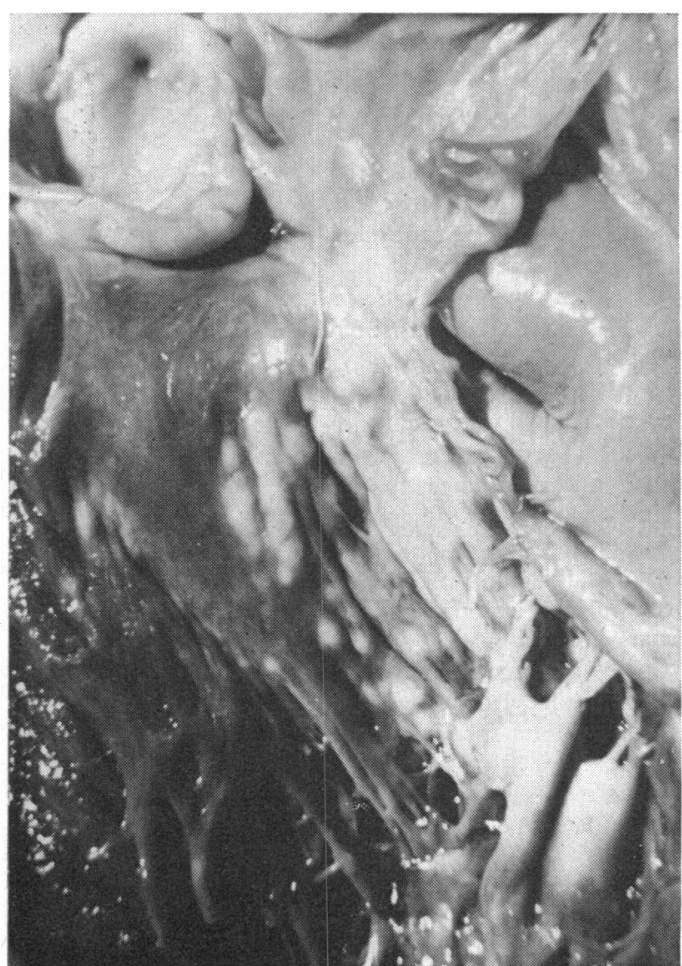

infiltrated with polymorphs and surrounded by pallisading fibroblasts, lymphocytes, and plasma cells. Others consisted of focal areas of degenerating muscle fibres with varying degrees of polymorph infiltration. There was also much fibrosis adjacent to these granulomata.

The myocardium also showed a deeper and widespread patchy fibrosis and there were some lymphocytes, plasma cells, and histiocytes scattered in the interstitial tissue.

Granulomata were present in the bases of the aortic, mitral, and tricuspid valves. There was a large necrotic nodule expanding the right coronary cusp of the aortic valve at its base and several smaller nodules in the centre of the leaflet, which showed no polymorph infiltration and were identical with the typical subcutaneous nodule.

Conducting tissue The sinoatrial node was normal. The His-Tawara system was sectioned by the method of Hudson (1963). Sections showed a large necrotic nodule associated with much haemorrhage and heavy infiltration of polymorphs and plasma cells in the region of the ruptured sinus of Valsalva. The haemorrhagic nodule extended from just above the tricuspid valve, across the atrioventricular ring to the left ventricular endocardial surface (Fig. 4). A few remain-

FIG. 2 Probe inserted into the origin of the sinus track behind the noncoronary cusp of the aortic valve. Note the thickening of the right coronary cusp. 

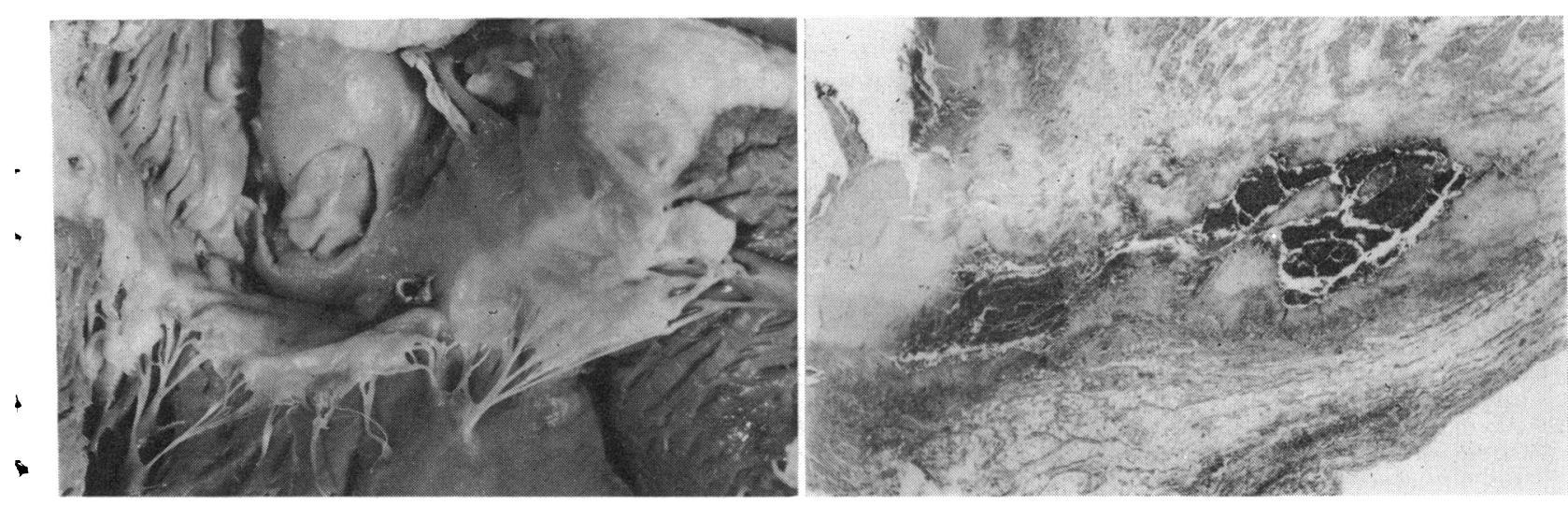

FIG. 3 Exit of the sinus track into the right atrium immediately above the tricuspid valve.
FIG. 4 Haemorrhage into the rheumatoid nodule in the region of the atrioventricular node. The right atrial cavity is seen at the upper left corner and the left ventricular cavity below and to the right. (Haematoxylin and eosin $\times 4$.) ing fibres of the atrioventricular node and the bundle of $\mathrm{His}$ were present in this region but were

- heavily infiltrated with polymorphs and red blood cells.

4. Special staining revealed no evidence of amyloid disease and there were no signs of a generalized arteritis.

\section{Discussion}

- In rheumatoid arthritis two types of pathological process have been described, which involve the heart: non-specific chronic inflammatory changes, and the typical rheumatoid granuloma. The nonspecific type of inflammation is usually responsible for the pericarditis, which is the commonest lesion in rheumatoid arthritis, being found at necropsy in approximately 30 per cent of cases (Kirk and Cosh, 1969). A similar process may affect the endocardium and myocardium (Sinclair and Cruickshank, 1956).

Cardiac rheumatoid granulomata are found in 3 to 5 per cent of cases at necropsy (Lebowitz, 1963; Cruickshank, 1958) and may also affect any part of the heart. They are often clinically silent but may present with signs of valve lesions, cardiac failure, or arrhythmias. The case reported here showed the clinical features of severe aortic regurgitation which was due to distortion of the valve ring and cusps by rheumatoid nodules. This is the most frequently seen valve lesion in rheumatoid arthritis (Weintraub and Zvaifler, 1963; Cari. penter, Golden, and Roberts, 1967; Lefkovits, Kaplan, and Young, 1968), but aortic stenosis > (Lassiter and Tassy, 1965) and mitral regur- gitation (Carpenter et al., 1967) have also been described. Nodules have been found in all four valves (Roberts et al., 1968) but only in the aortic and mitral valves have they caused significant stenosis or regurgitation.

Conduction defects are rare, but one case of first degree heart block (Kirk and Cosh, 1969), one of left bundle-branch block (Carpenter et al., 1967), and three of complete heart block (Handforth and Woodbury, 1959; Gowans, 1960; Harris, 1970) have been reported, in which there was histological evidence of interruption of the conducting tissue by rheumatoid nodules. In this case, though there was a large rheumatoid granuloma in the region of the atrioventricular node, sinus rhythm with normal conduction was maintained until just before death. The terminal event was undoubtedly haemorrhage into this nodule which ruptured the sinus of Valsalva and destroyed the atrioventricular node. To our knowledge, this is the first occasion in which such haemorrhage or rupture of any part of the heart has been associated with a rheumatoid nodule. It is possible that the anticoagulants the patient was receiving may have contributed to the haemorrhage, but we feel this to be unlikely as control was satisfactory and there was no evidence of bleeding elsewhere.

We wish to thank Dr. A. C. Boyle, Dr. Richard Emanuel, and Dr. D. L. Woolf, for permission to publish this case report. Our thanks are also due to Mrs. J. Oxbrow for her assistance in the preparation of the cardiac conduction tissue. 


\section{References}

Bagenstoss, A. H., and Rosenberg, E. F. (194I). Cardiac lesions associated with chronic infectious arthritis. Archives of Internal Medicine, 67, $24 \mathrm{r}$.

Carpenter, D. F., Golden, A., and Roberts, W. C. (1967). Quadrivalvular rheumatoid heart disease associated with left bundle branch block. American Fournal of Medicine, 43, 922.

Cruickshank, B. (1958). Heart lesions in rheumatoid disease. Fournal of Pathology and Bacteriology, 76, 223.

Gowans, J. D. C. (1960). Complete heart block with Stokes-Adams syndrome due to rheumatoid heart disease. New England fournal of Medicine, 262, Ior2.

Handforth, C. P., and Woodbury, J. F. L. (1959). Cardiovascular manifestations of rheumatoid arthritis. Canadian Medical Association fournal, 80, 86.

Harris, M. (1970). Rheumatoid heart disease with complete heart block. Fournal of Clinical Pathology, 23,623 .

Hudson, R. E. B. (1963). The human conductingsystem and its examination. Fournal of Clinical Pathology, 16, 492.

Kirk, J., and Cosh, J. (1969). The pericarditis of rheumatoid arthritis. Quarterly fournal of Medicine, 38, 397.

Lassiter, G. S., and Tassy, F. T. (1965). Malignant rheumatoid disease with aortic stenosis. Archives of Internal Medicine, 116, 930.

Lebowitz, W. B. (1963). The heart in rheumatoid arthritis (rheumatoid disease). Annals of Internal Medicine, 58, 102.

Lefkovits, A., Kaplan, S. B., and Young, J. M. (1968). Rheumatoid granulomata of the aortic valve ring causing fatal aortic insufficiency in a patient with minimal arthritis. Arthritis and Rheumatism, II, 494.

Roberts, W. C., Kehoe, J. A., Carpenter, D. F., and Golden, A. (1968). Cardiac valvular lesions in rheumatoid arthritis. Archives of Internal Medicine, I22, I4I.

Sinclair, R. J. G., and Cruickshank, B. (1956). A clinical and pathological study of 16 cases of rheumatoid arthritis with extensive visceral involvement ('rheumatoid disease'). Quarterly fournal of Medicine, 25, 313.

Weintraub, A. M., and Zvaifler, N. J. (1963). The occurrence of valvular and myocardial disease in patients with chronic joint deformity. American fournal of Medicine, 35, 145.

Requests for reprints to Dr. Robin B. HedworthWhitty, Department of Cardiology, The Middlesex Hospital, Cleveland Street, London W.I. 